\title{
TREATMENT AND PROGNOSIS OF CATARRHAL DEAFNESS IN YOUNG CHILDREN.*
}

\author{
BY J. ALOTSIUS MULLEN, M.D., HOUS'TON, TEXAS.
}

As we live in an age of preventive medicine, the importance of otitis media catarrhalis hypertrophica in very young children engages our attention from a proplylactic standpoint, and directs our enclearors to the isolation of the causes of this condition, and suggests the means by which they may be irrevocably removed and their results corrected, so that the consecutive pathological changes of chronic hypertrophic aural catarrh will have been prevented from occurring, thereby rescuing the patient from years of auditory incompetency and suflering.

There is a prevailing impression among the general profession, fostered and promulgated to a great extent by the text-books, that the prognosis of catarrbal deafness is more grave to the restoration of hearing, the younger the patient. In other words, the more juvenile the patient the more difficult it is to successfully treat these cases and carry them to a place of auditory safety.

The universality of this erroneous idea has rendered the profession, in its consideration for these cases, prophylactically apathetic, and has permitted numerous. children to become men and women greatly handicapped in life by severe and permanent obtundity of a very appreciable sense, hearing.

Children are in the formative period of their physical as well as their mental lives; and in children deafness is very frequently overlooked, or is not attributed to its true canse, and is so not made a matter of treatment. $f$ So then that any therapentic or surgical assistance rendered them during this time will be far more apt to remove the causes of catarrhal deafness and prevent the pathological changes in the middlè-ear contents and drum, so tending to permanency and dangerous to henring and the development of this sense pari-pasu with the other special senses which at this time more than any other depend so largely upon the assistance of audition for their associated action and development. Furthermore, if these cases are

\footnotetext{
*lend before the Sonthern Section of the Americun Laryngological, Rhinoloricil and Otologicul Society, New Or'lenus, Lil., March 3d, 1897.

†" System of Discases of Ear, Nose and Throut," Hurnett (Sexton), Vol. Ir., page 328.
} 
allowed to progress and their hearing become seriously affected, pari$p$ cosu with the development of this obtundity, the functional activity of the auditory center is nullified from non-use, the degree of which depending upon the length of time and the character of the cause of deafness. This same uarcosis of function may occur in any center or member of the body when the same is not in active use.

This point I have taken especial care to bring more fully before the profession at the last meeting of the Texas State Medical Association.*

The causes of deafuess in young children primarily produce obstruction either of air or circulation; they rencler the free passage of air difficult, and contribute to frequent circulatory disturbances, no matter what may be the character of the nasal, tubal or pharyngeal diserse present.

The obstruction interferes with the free entrance and preparation of air into the middle-enr, and also with the free circulation of blood in the mucous membrane lining the entire air tract.

The common causes of catarrhal denfness in the very young, are nasal polypi, hypertrophic rhinitis, adenoids, enlarged tonsils, etc. These produce obstruction of the air passages; materially interfere with the proper amount and normal preparation of air; while they also, with acute rhinitis, acute naso-pharyngitis, and acute salpingitis, produce catariral inflammation of the Eustachian tube, mucous membrane of the tympanum, and disturb the equilibrium of the circulation in this region.

The report of the following cases it is hoped will bring this subject under general discussion and serve to demonstrate the treatment used, and afford a modification of the generally accepted prognosis so frequently given by the profession at large, and to condemn the advice that "the child will outgrow his deafness." .

C. B. and J. B., brother and sister, aged respectively 7 and 9 yrs. Both mouth-breathers; they also had hypertrophic rhinitis and enlarged tonsils. Bone conduction + in both children and in both ears. It is heard by boy, R. F. 3 inch, L. E. 1 inch. The girl had same dullness. Whisper not heard in L. E. of either child, and with difficulty in the R.E. Voices had changed in character and intensity, with noticable inattention and lack of interest in their studies. 'Tinnitus present in both cases. Drums appreciably retracted and not freely movable. The rest of my cases show approximately the same histories, with the occasional presence of adenoid or polypoid growths. These two cases serve as a type sufficient to illustrate this class of cases and render the detailing of similar ones unnecessary.

*'Iexas State Medical Association 'Transactions, April 23d, 1806. 
The treatment adopted was in general terms about the same in all cases of catarrhal deafness in the young that come under my observation. It consists in the removal of adenoid or polypoid growths, hypertrophic tonsils, and the reduction of thickened nasal mucous membrane, combined with naso-pharyngeal and aural medication.

Fused chromic acid crystals were applied to pin down the hypertrophic mucosa. The patency of the Fustachian tubes must be insured; so also must there be guaranteed the free circulation and preparation of air, the prevention of vacillations of the circulations due to congestions, etc., or else treatment applied to deafness in the very young will not be productive of any permanent results, amounting merely to a waste of time and energy in a large number of cases. $\Lambda \mathrm{f}$ ter the thorough removal of all obstructions, I place more reliance in the daily use of the Seigel pneumatic speculum with Politzer bag attached than in any other applinnce or form of corrective treatment.

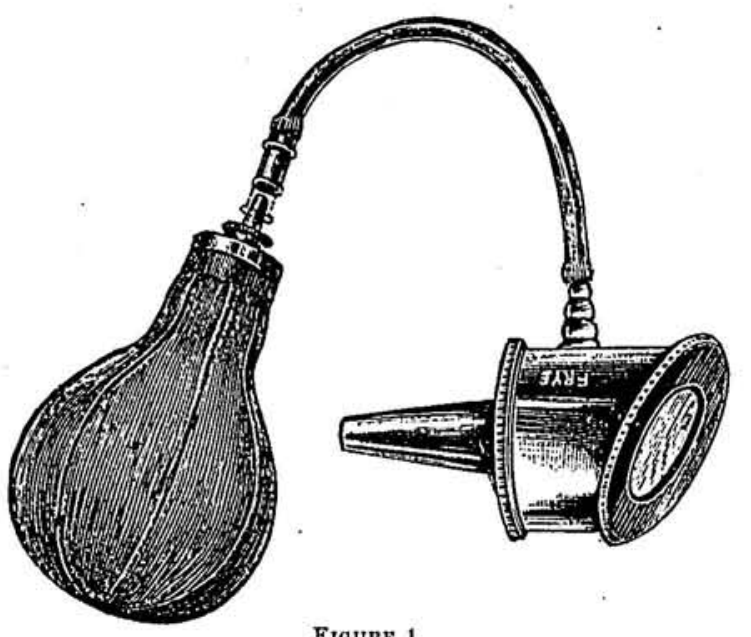

The membrana tympanum and ossicular articulations should be exercised gently every day for a sitting of three to five minutes' duration, with the speculum and Politzer bag attachment (Fig. 1). The membrana tympanum to be under illumination all the time. If indicated, the child should be given an alterative to improve the general health.

The hygiene of these cases is not by any means a matter of small importance, but should be considered of great utility and usefulness. The temperature of the sleeping apartment should be regular, and the air pure and easily renewed. Heated rooms absorb the nasal and pharyngeal secretions, and faciliate mouth breathing with all its at- 
tendant evils. These children should also be prohibited from sleeping in the same room with persons who have enlarged tonsils or any chronic throat aflections; and care exercised to keep them from going out in the night air. All forms of treatment for these little ones should be guided by mildness and gentleness; and always bear in mind that tissues are being dealt with which admit of great benefit or sovere injury; and never abuse the confidence of childhood. Furthermore, the aurist has not thoroughly completed his work and accomplished all possible for his little patient unless, after the removal of adenoids, enlarged tonsils, etc., he use some form of corrective mechanical treatment calculated to restore the tiansmitting structures of the middle ear to their conducting acuity.

602 Main St.

\section{Connection Between Word Deafness and Deafness.}

Word deafness has hitherto been ascribed to a cerebral lesion, but Keller and Freund have recently been impressed with the important connection between it and disturbances of the ears, especially of the labyrintl, which is able alone to cause word deafuess. They urge the necessity of investigation of the ears in such cases. Keller asserts that isolated speech cleafness, with retained ability to comprehend other sounds, often corresponds with bilateral aflections of the labyrinths, and is dependent upon tone-gaps in that portion of the tone scale which is physiologically important for the comprehension of speech. It sometimes happens that bilateral ear affections which in themselves are not sufficient to cause word deafness, produce it by a secondary degeneration of the nerve tracts and auditory centers. It requires such supreme eflorts of attention then to hear that the patient gradually renounces the attempt, and lack of use hastens the degenerative processes. This is demonstrated by Urbantschitsch's system of ear gymnastics, which does not so much improve the hearing as it arouses and practices the faculty of comprehending what is heard. Pick's case is instructive in this respect. The patient was exceedingly hard of hearing with word deafness also, and yet no lesion of the enrs could be ascertained. The necropsy revealed, however, great alterations in the temporal lobe, to which the sensory aphasia was undoubtedly due.-Deutsche Mecl. Woch. 